\title{
Monoallelic expression of MAO-A in skin fibroblasts
}

\author{
N. Nordquist $\cdot$ L. Oreland
}

Published online: 26 August 2009

(C) Springer-Verlag 2009

It has been brought to our attention that this article represents a duplicate publication of an article originally published in the journal "Biochemical and Biophysical Research Publications" by Elsevier (N. Nordquist, L. Oreland in Biochemical and Biophysical Research Publications 348:763-767, 2006).

After carefully checking the circumstances with the Editor-in-Chief and the responsible author, this was an unfortunate result stemming from a misunderstanding which occurred in the course of the preparation of this Special Issue of Journal of Neural Transmission.
In order to appropriately correct this situation and to comply with Springer's Policy of Publishing Integrity, which also follows the recommendations of COPE, we have therefore agreed with the author as well as the publisher of the first publication to the retraction of this article. Journal of Neural Transmission sincerely regrets the circumstances that have led to this situation and any inconvenience that might have arised.

The online version of the original article can be found under doi:10.1007/s00702-007-0676-X.

N. Nordquist $(\bowtie) \cdot$ L. Oreland

Department of Neuroscience, Uppsala University,

Uppsala, Sweden

e-mail: niklas.nordquist@neuro.uu.se 